\title{
The association between frequency of eating out with overweight and obesity among children aged 6- 17 in China: A National Cross-sectional Study
}

\section{Yanning ma}

Chinese Center for Disease Control and Prevention National Institute for Nutrition and Health

\section{Weiyan Gong}

Chinese Center for Disease Control and Prevention National Institute for Nutrition and Health

\section{Caicui Ding}

Chinese Center for Disease Control and Prevention National Institute for Nutrition and Health

\section{Chao Song}

Chinese Center for Disease Control and Prevention National Institute for Nutrition and Health

\section{Fan Yuan}

Chinese Center for Disease Control and Prevention National Institute for Nutrition and Health

\section{Jing Fan}

Chinese Center for Disease Control and Prevention National Institute for Nutrition and Health

\section{Ganyu Feng}

Chinese Center for Disease Control and Prevention National Institute for Nutrition and Health

\section{Zheng Chen}

Chinese Center for Disease Control and Prevention National Institute for Nutrition and Health

Ailing Liu ( $\square$ liual@ninh.chinacdc.cn)

https://orcid.org/0000-0001-6886-2158

\section{Research article}

Keywords: China, eating out, frequency, overweight and obesity, children

Posted Date: October 20th, 2020

DOI: https://doi.org/10.21203/rs.3.rs-46043/v2

License: (c) (1) This work is licensed under a Creative Commons Attribution 4.0 International License. Read Full License

Version of Record: A version of this preprint was published at BMC Public Health on May 28th, 2021. See the published version at https://doi.org/10.1186/s12889-021-11104-0. 


\section{Abstract}

Background: In parallel with the increased prevalence of childhood overweight and obesity, the rate of eating out in China has increased dramatically in recent years. The purpose of the study was to explore the association between frequency of eating out with overweight and obesity among Chinese children.

Methods: The representative sample of Chinese children aged 6-17 years (7685 boys; 7576 girls) was recruited from Chinese National Nutrition and Health Survey (CNNHS) in 2010-2012. Frequency of eating out was collected by interview-administered questionnaire and categorized as: less than once per week, once and twice per week, and three times or more per week. Height and weight were measured (body mass index was consequently calculated).

Results囚The prevalence of eating out among Chinese children aged 6-17 years old was $23.2 \%$. Children who ate out $0,1-2, \geq 3$ times per week were accounted for $76.8 \%, 10.9 \%$ and $12.3 \%$ respectively. Findings revealed that eating out three times per week or more was statistically significant associated with higher prevalence of overweight and obesity among boys ( $O R=1.20,95 \mathrm{Cl}: 1.04-1.38)$ compared with those ate out less than three times per week. However, no significantly association was observed among girls (OR=0.91, 95Cl:0.78-1.01). In additional, Younger children, rural children, children from low income family, those with leisure exercises (certain physical activities regularly carried out such as swimming, walking, running, equipment fitness), leisure time sedentary behaviors $(\mathrm{LTSB})(>2 \mathrm{~h} / \mathrm{d})$ were relatively more likely to eat out.

Conclusions: The results illustrated that eating out three times or more had a significantly positive effect on overweight and obesity among boys in China.

\section{Background}

The worldwide prevalence of overweight and obesity among children is becoming a global health problem[1][1,2]. Between 1980 and 2013, the prevalence of overweight and obesity among children has increased by 47.1 percent globally[3]. Increases were observed in both developed countries and developing societies [4]. The number of childhood overweight and obesity also increased dramatically over the past decades in China[5].A recently report among Chinese students aged 7-18 years old showed that the nationwide prevalence of overweight and obesity increased from $2.1 \%$ to $12.2 \%, 0.5 \%$ to $7.3 \%$ from 1985 to 2014, respectively, and this proportion was expected to reach $28 \%$ or affected 3496 million children by $2030[6]$. The previous studies suggested that overweight and obesity children had an risk of adult obesity[7], which will result to an increased morbidity and mortality[8,9]. Childhood overweight and obesity correlate with heart disease, high blood pressure and other chronic disease[10]. Childhood overweight and obesity is attributed to complex interaction of genetic, environmental, social and behavior factors[11-12].

With rapid economic development, the dietary structure and eating behaviors have undergone great changes[13,14], eating out has become a continuously growing part of the Chinese dietary pattern. 
According to the statistics released by China's National Bureau of Statistics, carting revenue increased from 74.03 billion RMB in 2002 to 441.99 billion RMB in 2012, which raised almost 5 times[15].In terms of eating out associate with higher intake of total energy, total fat, sodium, and sugar and lower intakes of fiber, vitamins, and minerals [16,17],the available data have suggested that eating at restaurant may increase the consumption of meat, sweet while reducing the intake of grains, vegetables and fruits[18]. Furthermore, a large numbers of literatures have indicated that eating out was associated with higher intake of energy[16-19], the increasing energy intake from restaurant drove overall increase in daily energy[20]. thus it may contribute to energy unbalanced that cause weight gain[16]. As number of eating out occasion continues to increase, more attention are paid to the relationship between eating out with overweight and obesity.

Aristides[21] et al demonstrated that children who ate at restaurant had a $21 \%$ higher risk of being overweight than those who did not eat at restaurant. Many abroad studies were conducted by nationally representative or large cohort data from west countries. A research[22] of 3-12 years children in 9 areas of China found the positive relationship between eating out and risk of overweight and obesity or BMI, mainly due to the substantial contribute of eating out to increase the energy intake[23]. A study [24] of Guangzhou middle school students reported that those consuming restaurant food once a week or more was associated with a $38 \%$ higher prevalence, compared with those who never ate at restaurant after adjusting for age, single child family structure, household income, and culture of students' parents. However, available data on the association between eating out and overweight and obesity among Chinese children are far from conclusive. Besides the data of previous published was not representative of the national children population. The objective of the current study was to examine the association between frequency of eating out with overweight and obesity in a nationally representative sample of children using the data of Chinese Nutrition and Health Surveillance (CNNHS) in 2010-2012., then to provide basic information to aid in developing eating out intervention strategies.

\section{Methods}

\section{Study participants}

Data used in this study were from the Chinese Nutrition and Health Surveillance (2010-2012). The CNNHS was a nationally representative cross-sectional study conducted by the National Institute for Nutrition and Health, Chinese Center for Disease Control and Prevention (NINH, China CDC) to assess the health and nutrition status of Chinese residents. The 2010-2012 survey covered all 31 provinces, autonomous regions, and municipalities directly under the central government throughout China (except for Taiwan, Hong Kong, and Macao). The method of multi-stage stratification and population proportional cluster random sampling was adopted. In accordance with economic development, all county-level administrative units were divided into four categories: big cities, small and medium-sized cities, ordinary rural areas and poor rural areas. A total of 150 counties (districts) were selected from four categories of areas as study sites $\$ including 34 big cities, 41 small and medium-sized cities, 45 ordinary rural areas and 30 poor rural areas, respectively. The study selected 25 households randomly from each 
village/community and children aged 6 to 17 years in each family were involved. If the number of children was less than 20 children (10 boys and 10 girls) in each age group in each site, supplementary children would be selected from nearby primary and secondary schools to meet the minimum sample size. The specific sampling method can be referred in the published literature [25]. After excluding missing and abnormal data in height, weight, frequency of eating out and sedentary time, a total of 15261 participants ( 7685 boys, 7576 girls) aged 6 to 17years were recruited. This study was approved by the ethics review committee of the National Institute for Nutrition and Food Safety, Chinese Center for Disease Control and Prevention (No. 2013-018).All participants' parents or legal guardian were fully informed the purpose and procedures of the study before enrolling and signed the informed consent.

\section{Data collection}

The interview-administered questionnaire was used to collect the information of basic socio-economics, sedentary duration and leisure exercise. The food frequency questionnaire (FFQ) was used to collect eating behaviors over the past week. Participants were asked "How many times have you had breakfast, lunch, or dinner in the past week (seven days)?" and subsequently "How many times in the past week have you had breakfast, lunch, or dinner at a restaurant or school canteen?". All the questionnaires were collected by trained investigator by face-to-face interview, and the interviews were conducted at the homes of the participants. The children younger than 12 years old finished the questionnaire with the help of their parents or legal guardian. To ensure the reliability of data, evaluation indexes and quality control measures were made at the national, provincial and district levels, quality control was carried out in the early stage, later stage and period of field survey.

\section{Categories of Frequency of Eating Out}

In the current study, eating out was defined as eating a meal or more prepared by restaurants. Frequency of eating out was categorized as three levels: 0 time, 1-2 times, or 3 times and over per week.

\section{Anthropometric Measurements}

The height was measured with an accuracy of $0.1 \mathrm{~cm}$ and the fasting weight was measured with an accuracy of $0.1 \mathrm{~kg}$. All measurements were conducted by well-trained investigators under standard operation procedure. Body mass index (BMI) was calculated as a division of weight in kilograms by the square of height in meters.

\section{Definition of Weight Status}

Overweight and obesity was classified based on age- and gender-specific BMI cutoff points among Chinese children[26]. In the meantime, national health standard of Screening standard for malnutrition of school-age children and adolescents was devoted to screen for underweight children[27].

\section{Assessment of Sociodemographic Determinants}


Age groups were divided into two categories (6-12, 13-17 years). Participants were divided into four residency groups according to location (urban, suburban, rural and poor rural). Family income was classified into four levels ( $<20,000 \mathrm{RMB} /$ person, 20,000-40,000 RMB/person, $>40,000 \mathrm{RMB} /$ person, and unkown). Leisure exercise was defined as two levels (No/Yes). Sedentary duration status was grouped into two levels $(\leq 2 h / d$ and $>2 h / d)$.

\section{Statistical Analysis}

All statistical analyses were conducted using SPSS 22.0. The univariate descriptive statistics were conducted for each variable (frequency and percentage), and the frequency of eating out was expressed as a percentage. $t$ tests were used to compare means between different gender, age,leisure exercise and leisure SB groups. Data were run to compare means of region, family-income and BMI status using Chisquare tests. Multivariate logistic regression analysis was used to analyze the relationship between eating out and overweight and obesity. After adjusting for age, region, logistic regression was employed to examine the association of eating out with overweight and obesity, where dependent variable was BMI status (obesity, overweight, normal weight and underweight), and adjusted odds ratios (OR) with 95\% confidence intervals $(\mathrm{Cl})$ were obtained. Statistical significance was considered at $p<0.05$.

\section{Results}

\section{The distribution of the characteristics among participants}

The characteristics of participants were presented in Table 1. Children who ate out 0, 1-2 and $\geq 3$ times per week were accounted for $76.8 \%, 10.9 \%$ and $12.3 \%$, respectively. Although no significant gender difference in frequency of eating out was observed, we found that there was a trend that children from economic developed region and low income family eat out more often $(P<0.05)$. Compared with their counterparts, younger children, those with leisure exercise, leisure $S B(>2 \mathrm{~h} / \mathrm{d})$ were more likely to eat out $(P<0.05)$. In additional, table 1 shows the frequency distribution of eating out is significantly different among children with different weight status $(P<0.05)$.

Table 1 Demographic characteristics of participant 


\begin{tabular}{|c|c|c|c|c|c|c|}
\hline \multirow[t]{3}{*}{ Variables } & \multirow[t]{2}{*}{ Total } & \multicolumn{3}{|c|}{ Eating-out\times/ week】 } & \multirow[t]{3}{*}{$c^{2}$} & \multirow[t]{3}{*}{$P$} \\
\hline & & 0 & $1-2$ & $\geq 3$ & & \\
\hline & $\mathrm{N}$ & $N \otimes \% \bigotimes$ & $N \otimes \% \bigotimes$ & $N \rrbracket \% \bigotimes$ & & \\
\hline Total & 15261 & $11724 \rrbracket 76.8 \rrbracket$ & 1668ه10.9凶 & 1869ه12.3囚 & & \\
\hline Gender & & & & & 3.47 & 0.177 \\
\hline Boys & 7685 & $5887 \rrbracket 50.2 \rrbracket$ & $822 \varangle 49.3 \rrbracket$ & $976 \bigotimes 52.2 \rrbracket$ & & \\
\hline Girls & 7576 & $5837 ه 49.8 \rrbracket$ & 846ख50.7凶 & 893®47.8\ & & \\
\hline Age $\Downarrow$ years $\rrbracket$ & & & & & 98.52 & $<0.05$ \\
\hline 6-12 & 9436 & 7491囚63.9ه & $956 \bowtie 57.3 \rrbracket$ & $989 \llbracket 52.9 \rrbracket$ & & \\
\hline $13-17$ & 5825 & $4233 \rrbracket 36.1 \rrbracket$ & 712ه42.7凶 & $880 \rrbracket 47.1 \rrbracket$ & & \\
\hline Region & & & & & 1127.52 & $<0.05$ \\
\hline Urban & 3987 & $2455 \rrbracket 20.9 \rrbracket$ & 696ه41.7凶 & 838ه44.7区 & & \\
\hline Suburban & 4164 & 2996ه25.6区 & $551 \rrbracket 33.0 \rrbracket$ & $617 \rrbracket 33.0 \rrbracket$ & & \\
\hline Rural & 5053 & $4455 \rrbracket 38.0 \rrbracket$ & $253 \rrbracket 15.2 \rrbracket$ & $345 \rrbracket 18.5 \rrbracket$ & & \\
\hline Poor rural & 2057 & 1818ه15.5区 & 168ه10.1》 & 71区3.8区 & & \\
\hline Family income & & & & & 362.46 & $<0.05$ \\
\hline Low & 9156 & 7469ه63.7区 & $773 \rrbracket 46.4 \rrbracket$ & 914ه48.9凶 & & \\
\hline Medium & 2348 & 1645ه14.0区 & 331凶19.8凶 & $372 \bigotimes 19.9 \rrbracket$ & & \\
\hline High & 672 & 386『3.3】 & 147囚8.8区 & $139 \rrbracket 7.4 \rrbracket$ & & \\
\hline Unknown & 3085 & $2224 \rrbracket 19.0 \rrbracket$ & $417 \rrbracket 25.0 \rrbracket$ & $444 \llbracket 23.8 \rrbracket$ & & \\
\hline Leisure exercise & & & & & 285.49 & $<0.05$ \\
\hline No & 8831 & 7219ه61.6ه & $767 \rrbracket 46.0 \rrbracket$ & $845 \rrbracket 45.2 \rrbracket$ & & \\
\hline Yes & 6430 & $4505 \rrbracket 38.4 \rrbracket$ & $901 \rrbracket 54.0 \bigotimes$ & $1024 \rrbracket 54.8 \rrbracket$ & & \\
\hline Leisure SB & & & & & 150.01 & $<0.05$ \\
\hline$\leq 2 \mathrm{~h} / \mathrm{d}$ & 5880 & $4824 \rrbracket 41.2 \rrbracket$ & $526 \rrbracket 31.5 \rrbracket$ & $530 \rrbracket 28.4 \rrbracket$ & & \\
\hline$>2 \mathrm{~h} / \mathrm{d}$ & 9381 & $6900 \rrbracket 58.8 \rrbracket$ & 1142ð68.5】 & 1339ه71.6ه & & \\
\hline BMI status & & & & & 35.34 & $<0.05$ \\
\hline Obesity & 1622 & $1212 \bigotimes 10.3 \rrbracket$ & 189ه11.3ه & 221ه11.8ه & & \\
\hline Overweight & 2015 & 1499ه12.8\ & 231ه13.9ه & 285ه15.3》 & & \\
\hline
\end{tabular}




\begin{tabular}{|lllll|} 
Normal & 10692 & $8238 \rrbracket 70.3 \rrbracket$ & $1181 \rrbracket 70.8 \rrbracket$ & $1273 \rrbracket 68.1 \rrbracket$ \\
\hline Underweight & 932 & $775 \llbracket 6.6 \rrbracket$ & $67 \rrbracket 4.0 \rrbracket$ & $90 \rrbracket 4.8 \rrbracket$ \\
\hline
\end{tabular}

\section{Logistic regression analysis of the relationship between frequency of eating out with overweight and obesity}

The relationship between frequency of eating out with overweight and obesity are presented in table 2 . In logistic regression model ,after adjustment for age, gender, region, family income, leisure exercise and leisure SB, those who ate out 3 times or more per week had a higher risk of overweight and obesity (OR $=1.21,95 \% \mathrm{Cl}$ : 1.03-1.41) in boys group, compared to those who ate out less than 3 times a week. No significant relationship was observed among girls $(\mathrm{OR}=0.91,95 \mathrm{Cl}$ : 0.78-1.01).

Tale 2 Logistic regression analysis of frequency of eating out and overweight and obesity 


\begin{tabular}{|c|c|c|c|c|c|c|}
\hline \multirow[t]{2}{*}{ Variables } & \multicolumn{2}{|l|}{ Total } & \multicolumn{2}{|l|}{ Boys } & \multicolumn{2}{|l|}{ Girls } \\
\hline & ORヌ95\%Cl】 & $\mathrm{P}$ & OR $95 \% \mathrm{Cl}$ & $\mathrm{P}$ & OR $\otimes 95 \% \mathrm{Cl}$ & $\mathrm{P}$ \\
\hline \multicolumn{7}{|c|}{ Eating-out $\triangle$ freq./ week $\rrbracket$} \\
\hline 0 & Reference & & & & & \\
\hline $1-2$ & $\begin{array}{l}1.04(0.92- \\
1.18)\end{array}$ & 0.54 & $\begin{array}{l}1.15(0.97- \\
1.37)\end{array}$ & 0.10 & $\begin{array}{l}0.96(0.74- \\
1.11)\end{array}$ & 0.32 \\
\hline$\geq 3$ & $\begin{array}{l}1.09(0.96- \\
1.23)\end{array}$ & 0.19 & $\begin{array}{l}1.21(1.03- \\
1.41)\end{array}$ & $<0.05$ & $\begin{array}{l}0.92(0.76- \\
1.12)\end{array}$ & 0.41 \\
\hline \multicolumn{7}{|c|}{ Age $\rrbracket$ years $\rrbracket$} \\
\hline $6-12$ & Reference & & & & & \\
\hline $13-17$ & $\begin{array}{l}0.62(0.57- \\
0.68)\end{array}$ & $<0.05$ & $\begin{array}{l}0.56(0.50- \\
0.63)\end{array}$ & $<0.05$ & $\begin{array}{l}0.69(0.60- \\
0.79)\end{array}$ & $<0.05$ \\
\hline \multicolumn{7}{|l|}{ Region } \\
\hline urban & Reference & & & & & \\
\hline suburban & $\begin{array}{l}0.88(0.79- \\
0.98)\end{array}$ & $<0.05$ & $\begin{array}{l}0.78(0.68- \\
0.89)\end{array}$ & $<0.05$ & $\begin{array}{l}1.03(0.88- \\
1.22)\end{array}$ & 0.72 \\
\hline rural & $\begin{array}{l}0.73(0.65- \\
0.81)\end{array}$ & $<0.05$ & $\begin{array}{l}0.64(0.56- \\
0.74)\end{array}$ & $<0.05$ & $\begin{array}{l}0.84(0.71- \\
0.99)\end{array}$ & $<0.05$ \\
\hline Poor rural & $\begin{array}{l}0.65(0.56- \\
0.75)\end{array}$ & $<0.05$ & $\begin{array}{l}0.54(0.44- \\
0.66)\end{array}$ & $<0.05$ & $\begin{array}{l}0.81(0.65- \\
1.04)\end{array}$ & 0.07 \\
\hline \multicolumn{7}{|l|}{$\begin{array}{l}\text { Family } \\
\text { income }\end{array}$} \\
\hline Low & Reference & & & & & \\
\hline Medium & $\begin{array}{l}1.22(1.10- \\
1.37)\end{array}$ & $<0.05$ & $\begin{array}{l}1.32(1.14- \\
1.53)\end{array}$ & $<0.05$ & $\begin{array}{l}1.11(0.93- \\
1.33)\end{array}$ & 0.23 \\
\hline High & $\begin{array}{l}1.26(1.05- \\
1.51)\end{array}$ & $<0.05$ & $\begin{array}{l}1.37(1.08- \\
1.74)\end{array}$ & $<0.05$ & $\begin{array}{l}1.07(0.79- \\
1.45)\end{array}$ & 0.68 \\
\hline \multicolumn{7}{|l|}{$\begin{array}{l}\text { Leisure } \\
\text { exercise }\end{array}$} \\
\hline No & Reference & & & & & \\
\hline Yes & $\begin{array}{l}1.19(1.10- \\
1.29)\end{array}$ & $<0.05$ & $\begin{array}{l}1.16(1.04- \\
1.30)\end{array}$ & $<0.05$ & $\begin{array}{l}1.19(1.05- \\
1.35)\end{array}$ & $<0.05$ \\
\hline \multicolumn{7}{|l|}{ Leisure SB } \\
\hline$\leq 2 \mathrm{~h} / \mathrm{d}$ & Reference & & & & & \\
\hline$>2 \mathrm{~h} / \mathrm{d}$ & $1.11(1.02-$ & $<0.05$ & 1.08(096- & 0.19 & 1.16(1.01- & $<0.05$ \\
\hline
\end{tabular}




\section{Discussion}

With rapid economic development, the dietary structure and lifestyle have changed greatly. The study found that more than half of children ate out, which was higher than the national average of $28.3 \%$ as reported by the China National Health and Nutrition Survey in 2002. In parallel with an increase in the prevalence of overweight and obesity among children, the rate of eating out has increased rapidly in recent years. The current study clearly demonstrated the significant association between overweight and obesity with higher frequency of eating outside among boys, similar results were observed in previous researches: as in Brazilian children[28], and had been found among children from Etiology of Childhood Obesity (ECHO) study[29], in children and adolescents aged 11-14 years in London Borough[30]囚in Portugal children[21] and in US elementary schools students[31]. However, we did not observe a significant association between obesity and eating out in group of girls, which may due to boys' greater preference for fatty food and girls pay more attention to their weight[32-34]. whereas, the result of the UK National Diet and Nutrition Survey (NDNS) indicated that no association between energy intake and frequency of consumption of meals out in children[35].The differences in research result may be partly due to the fact that lacking of uniform standard for the definition of eating out. The definition for our research was refer to restaurant only, not including take-away food, the scope is relatively limited. Moreover, at present, our research data are mainly from the results of the 2010-2012 survey, as the catering industry has developed rapidly in recent years. With the intensive distribution of restaurant and the convenience of online catering service, children have easy access to eat out. The frequency of eating out of children probably present a growing trend. Therefore, strategies and interventions are warranted to target children's overall eating-out behavior, to prevent unhealthy eating behaviors among children, such as nutrition and health education.

Consistent with previous studies [19,36], 6-12 years children were more likely to be overweight and obesity compared with 13-17 years children, which may be related to the fact that younger children tended to eat out. One possible explanation from previous research $[37,38]$ suggested that the conception and behavior of healthy eating increases while children growing, older children tend to choose more healthy food. Thus, more researches are needed to provide dietary guidance of eating out on younger. Additionally, the study found that children from high-income household were associated with greater prevalence of overweight and obesity, the finding supported by previous researches [39,40]. Li Miao found that children from high income family with more pocket money were more likely to be overweight and obesity [41]. however, opposite to previous research[32] lower rate of frequency of eating out was found among children from high-income family, which may be related to the fact that the rate of overweight and obesity was higher among children from high-income family, then they were less likely to eat out . Furthermore, The study showed that in comparison with children in rural regions, children from urban regions tended to be overweight and obesity, and this difference was also found in other domestic studies[ 42,43], which was likely due to the convenience of eating out in the urban regions[44]. Similar result was founded in a 
survey conducted among Mexican children found that urban children[45] consumed more energy daily than those in the rural regions. Therefore, dietary nutrition education and intervention about healthy eating is necessary. As seen in the current study, children who do leisure exercise tended to eat out, this may be because doing exercise causes energy consumption, which leads children tend to foods produced and sold in restaurants with better taste, color, and flavor . leisure exercise was positive associated with high rate of overweight and obesity, which may be related to the fact that majority of childhood obesity prevention program conducted within obese rather than non-obese children [46], thus Obese children were more likely to participate in exercises[47]. We also found that children those had more leisure sedentary time tended to eat out. the similar result was found among Pakistan children aged 5 to 12 years showed that eating fast food had a significant association with sedentary behavior[48] and Matheson's study[49]. Sedentary lifestyle that included television viewing and playing video game, television advertising of restaurant foods were attractive for children, which was the possible explanation of the higher rate of eating out. Preventive strategies and practical approaches may need to reduce children's sedentary time.

The main advantages of this study were that the sample was nationally representative, which can reflect the nutrition and health status of Chinese children. The data gave a general description of eating out behavior of Chinese children aged 6-17 years, and the result provided a reference for further research with similar situation. Additionally, as eating out has become an integral part of the daily life, there are many studies on relationship between eating out and dietary patterns among children, while, insufficient guidance exists on the maximum recommended frequency of eating out. The result of this study provide reference times for eating out by genders. However, the present study had several limitations. Firstly, as the definition of eating out which including restaurant only. It is possible to underestimate the frequency of eating out; secondly, this study was cross-sectional study, the causal relationship between the eating out and overweight and obesity cannot be determined; finally, The calculated intake of nutrients such as energy is a lack, Only the data in the interview-administered questionnaire table are analyzed. Therefore, the conclusion of the study still has practical significance.

\section{Conclusion}

In conclusion, the result of this study demonstrated that the prevalence of eating out was $23.3 \%$ among Chinese children. Younger children, urban children and children from low-income family were more likely to eat out. Thus, dietary nutritional education and intervention about healthy eating is necessary. Considering the higher risk overweight and obesity among boys, interventions regarding eating out should tailor messages appropriately to target specific subjects by genders. From a public health perspective, the result suggested that interventions are needed to strengthen the monitoring of the situation of children eating out, thus contributing to reduce the potential enormous economic costs that are associated with eating out behavior-related illnesses, such as overweight and obesity.

\section{Declarations}

\section{Acknowledgments}


We thank all team members and participants for the China National and Health Survey (CHNHS 20102012).

\section{Funding}

The 2010-2012 CNNHS was supported by Medical Reform Major Program from the National Health and Family Planning Commission of the People's Republic of China (No.20120212).

\section{Availability of data and materials}

The datasets generated and/or analyzed during the current study are not publicly available because some results are still being analyzed but are available from the corresponding author on reasonable request.

\section{Authors' Contributions}

The authors' contributions were as follows: Y.M. participated in the data clean, data check and analysis, wrote the manuscript. A.L. designed the study and revised the manuscript.

W.G., C.D., C.S, F.Y., J.F.,G.F. and Z.C. collected and supervised the data. All authors red and approved the final manuscript.

\section{Ethics approval and consent to participate}

The protocol of the 2010-2012 CNNHS was approved by the Ethical Committee of NINH, China CDC (2013-018).

\section{Consent for publication}

Not applicable.

\section{Competing interests}

The authors declare that they have no competing interests.

\section{Author details}

Department of Nutrition and Health Education, National Institute for Nutrition and Health, Chinese Center for Disease Control and Prevention, No. 27 Nanwei Road, Xicheng District, Beijing 100050, China.

\section{Abbreviations}

Chinese National Nutrition and Health Survey(CNNHS); World Health Organization(WHO); National Institute for Nutrition and Health, Chinese Center for Disease Control and Prevention (NINH, China CDC); 
Confidence Intervals (95\% Cls); Etiology of Childhood Obesity (ECHO) ;UK National Diet and Nutrition Survey(NDNS) \Leisure time sedentary behaviors (LTSB)

\section{References}

1. World Health Organisation. Childhood overweight and obesity report. Report of a WHO consultation. WHO technical report series, no. 894. Geneva: World Health Organisation, 2015. http://www.who.int/dietphysicalactivity/childhood/en/

2. Sabin MA, Kao KT, Juonala M, Baur LA, Wake M: Viewpoint article: Childhood obesity-looking back over 50 years to begin to look forward. Journal of paediatrics and child health 2015, 51(1):82-86.

3. Ng M, Fleming T, Robinson M, Thomson B, Graetz N, Margono C, Mullany EC, Biryukov S, Abbafati C, Abera SF et al: Global, regional, and national prevalence of overweight and obesity in children and adults during 1980-2013: a systematic analysis for the Global Burden of Disease Study 2013. Lancet (London, England) 2014, 384(9945):766-781.

4. Gupta N, Shah P, Nayyar S, Misra A: Childhood obesity and the metabolic syndrome in developing countries. Indian journal of pediatrics 2013, 80 Suppl 1:S28-37.

5. Sun $\mathrm{H}, \mathrm{Ma} \mathrm{Y}, \mathrm{Han} \mathrm{D}$, Pan $\mathrm{CW}, \mathrm{Xu}$ Y: Prevalence and trends in obesity among China's children and adolescents, 1985-2010. PloS one 2014, 9(8):e105469.

6. Ma Guansheng, Mi Jie: Report on childhood obesity in China. People's Health Publishing House: Beijing, China, 2017:12.

7. Huang JY, Qi SJ: Childhood obesity and food intake. World journal of pediatrics : WJP 2015, 11(2):101-107.

8. Simmonds M, Burch J, Llewellyn A, Griffiths C, Yang H, Owen C, Duffy S, Woolacott N: The use of measures of obesity in childhood for predicting obesity and the development of obesity-related diseases in adulthood: A systematic review and meta-analysis. Health technology assessment (Winchester, England) 2015, 19:1-336.

9. Xu S, Xue Y: Pediatric obesity: Causes, symptoms, prevention and treatment. Experimental and therapeutic medicine 2016, 11(1):15-20.

10. Piernas C, Wang D, Du S, Zhang B, Wang Z, Su C, Popkin BM: Obesity, non-communicable disease (NCD) risk factors and dietary factors among Chinese school-aged children. Asia Pacific journal of clinical nutrition 2016, 25(4):826-840.

11. Silventoinen K, Rokholm B, Kaprio J, Sørensen TI: The genetic and environmental influences on childhood obesity: a systematic review of twin and adoption studies. International journal of obesity (2005) 2010, 34(1):29-40.

12. Janssen I, Katzmarzyk PT, Boyce WF, Vereecken C, Mulvihill C, Roberts C, Currie C, Pickett W: Comparison of overweight and obesity prevalence in school-aged youth from $\mathbf{3 4}$ countries and their relationships with physical activity and dietary patterns. Obesity reviews : an official journal of the International Association for the Study of Obesity 2005, 6(2):123-132. 
13. Seguin RA, Aggarwal A, Vermeylen F, Drewnowski A: Consumption Frequency of Foods Away from Home Linked with Higher Body Mass Index and Lower Fruit and Vegetable Intake among Adults: A Cross-Sectional Study. Journal of environmental and public health 2016, 2016:3074241.

14. Bezerra IN, Curioni C, Sichieri R: Association between eating out of home and body weight. Nutrition reviews 2012, 70(2):65-79.

15. National Bureau of Statistics: China Statistical Yearbook.China Statistics Press: Beijing,China, 2012

16. Jaworowska A, Blackham T, Long R, Taylor C, Ashton M, Stevenson L, Davies I: Nutritional composition of takeaway food in the UK.Nutrition \& Food Science 2014, 44:414.

17. Powell LM, Nguyen BT: Fast-food and full-service restaurant consumption among children and adolescents: effect on energy, beverage, and nutrient intake. JAMA pediatrics 2013, 167(1):14-20.

18. Seguin RA, Aggarwal A, Vermeylen F, Drewnowski A: Consumption Frequency of Foods Away from Home Linked with Higher Body Mass Index and Lower Fruit and Vegetable Intake among Adults: A Cross-Sectional Study. Journal of environmental and public health 2016, 2016:3074241.

19. Larson N, Neumark-Sztainer D, Laska MN, Story M: Young adults and eating away from home: associations with dietary intake patterns and weight status differ by choice of restaurant. Journal of the American Dietetic Association 2011, 111(11):1696-1703.

20. Lachat C, Nago E, Verstraeten R, Roberfroid D, Van Camp J, Kolsteren P: Eating out of home and its association with dietary intake: a systematic review of the evidence. Obesity reviews : an official journal of the International Association for the Study of Obesity 2012, 13(4):329-346.

21. Machado-Rodrigues AM, Gama A, Mourão I, Nogueira H, Rosado-Marques V, Padez C: Eating away from home: a risk factor for overweight in children. European journal of clinical nutrition 2018, 72(12):1724-1727.

22. Zhang $Y$, Wang J, Xue Y, Zheng Y, Wang P, Zhang Y: Investigation on relevant factors of eating out and fast food and overweight and obesity among 3-12 years old children in 9 areas of China. Zhong guo fu you bao jian = Maternal and Child Health Care of China 2014, 31:5132-5135.

23. Giovanna CA, Maria FG, Maria L, Catarina MA and Renata BL: The consumption of ultra-processed foods according to eating out occasions. Public Health Nutrition 2020, 236(3):1041-1048.

24. Deng J, Yang S, Ao I, Li B, Zou Z, Li L, Gao Y, Li L: Influencing factors of family eating out and its correlation withoverweight and obesity among urban fresh middle school students in Guangzhou City. Xian dai yi yao wei sheng = Journal of Modern Medicine \& Health 2019, 35(10):1455-1459.

25. Zhao, L, Ma, G, Piao, J, Zhang, J, YU D, HE Y, Huo, J, HU X, Yang X: Scheme of the 2010-2012 Chinese nutrition and health surveillance].Zhong hua yu fang yi xue za zhi = Chinese Journal of Preventive Medicine 2016, 50(3): 204-207.

26. Group of China Obesity Task Force Correspondence: Body mass index reference norm for screening overweight and obesity in Chinese children and adolescents. Zhonghua liu xing bing xue za zhi = Chinese Journal of Epidemiology 2004, 25(2):97-102. 
27. Dong YH, Wang ZH, Yang ZG, Wang XJ, Chen YJ, Zou ZY, Ma J: Epidemic status and secular trends of malnutrition among children and adolescents aged 7-18 years from 2005 to 2014 in China. Bei jing yi ke da xue xue bao = Journal of Peking University Health sciences 2017, 49(3) :424-432.

28. Bezerra IN, de Moura Souza A, Pereira RA, Sichieri R: Contribution of foods consumed away from home to energy intake in Brazilian urban areas: the 2008-9 Nationwide Dietary Survey. The British journal of nutrition 2013, 109(7):1276-1283.

29. Fulkerson JA, Farbakhsh K, Lytle L, Hearst MO, Dengel DR, Pasch KE, Kubik MY: Away-from-home family dinner sources and associations with weight status, body composition, and related biomarkers of chronic disease among adolescents and their parents. Journal of the American Dietetic Association 2011, 111(12):1892-1897.

30. Patterson R, Risby A, Chan MY: Consumption of takeaway and fast food in a deprived inner London Borough: are they associated with childhood obesity?BMJ open 2012, 2(3).

31. Ayala GX, Rogers M, Arredondo EM, Campbell NR, Baquero B, Duerksen SC, Elder JP: Away-fromhome food intake and risk for obesity: examining the influence of context. Obesity (Silver Spring, Md) 2008, 16(5):1002-1008.

32. Qiu C, Hou M: Association between Food Preferences, Eating Behaviors and Socio-Demographic Factors, Physical Activity among Children and Adolescents: A Cross-Sectional Study. Nutrients 2020, 12(3).

33. Kimura S, Endo Y, Minamimae K, Kanzaki S, Hanaki K: Gender differences in childhood food preference: evaluation using a subjective picture choice method. Pediatrics international : official journal of the Japan Pediatric Society 2014, 56(3):389-394.

34. Cooke LJ, Wardle J: Age and gender differences in children's food preferences. The British journal of nutrition 2005, 93(5):741-746.

35. Goffe L, Rushton S, White M, Adamson A, Adams J: Relationship between mean daily energy intake and frequency of consumption of out-of-home meals in the UK National Diet and Nutrition Survey. The international journal of behavioral nutrition and physical activity 2017, 14(1):131.

36. Adams J, Goffe L, Brown T, Lake AA, Summerbell C, White M, Wrieden W, Adamson AJ: Frequency and socio-demographic correlates of eating meals out and take-away meals at home: cross-sectional analysis of the UK national diet and nutrition survey, waves 1-4 (2008-12). The international journal of behavioral nutrition and physical activity 2015, 12:51.

37. Rogers I, Emmett P: The effect of maternal smoking status, educational level and age on food and nutrient intakes in preschool children: results from the Avon Longitudinal Study of Parents and Children. European journal of clinical nutrition 2003, 57(7):854-864.

38. Dovey TM, Staples PA, Gibson EL, Halford JC: Food neophobia and 'picky/fussy' eating in children: a review. Appetite 2008, 50(2-3):181-193.

39. Lachat C, Khanh le NB, Khan NC, Dung NQ, Nguyen do VA, Roberfroid D, Kolsteren P: Eating out of home in Vietnamese adolescents: socioeconomic factors and dietary associations. The American journal of clinical nutrition 2009, 90(6):1648-1655. 
40. Zang J, Luo B, Wang Y, Zhu Z, Wang Z, He X, Wang W, Guo Y, Chen X, Wang C et al: Eating Out-ofHome in Adult Residents in Shanghai and the Nutritional Differences among Dining Places. Nutrients 2018, 10(7).

41. Li M, Xue H, Jia P, Zhao Y, Wang Z, Xu F, Wang Y: Pocket money, eating behaviors, and weight status among Chinese children: The Childhood Obesity Study in China mega-cities. Preventive medicine 2017, 100:208-215.

42. Ma J, Cai C, Wang H, Dong B, Song Y, Hu P, zhang B: Trends in overweight and obesity among Chinese children of 7- 18 years old during 1985-2010. Zhong hua yu fang yi xue za zhi = Chinese Journal of Preventive Medicine 2012, 46(9):776-780.

43. Wang S, Dong Y, Wang Z, Zou Z, Ma J: Trends in overweight and obesity among Chinese children of 7- 18 years old during 1985-2014. Zhong hua yu fang yi xue za zhi = Chinese Journal of Preventive Medicine 2017, 51(4):300-305.

44. Du WW, Zhang B, Wang HJ, Wang ZH, Su C, Zhang JG, Zhang J, Jia XF, Jiang HR: Gender difference in the association between food away-from-home consumption and body weight outcomes among Chinese adults. Public health nutrition 2016, 19(16):2984-2990.

45. Taillie LS, Afeiche MC, Eldridge AL, Popkin BM: The contribution of at-home and away-from-home food to dietary intake among 2-13-year-old Mexican children. Public health nutrition 2017, 20(14):2559-2568.

46. Xu F, Ware RS, Leslie E, Tse LA, Wang Z, Li J, Wang Y: Effectiveness of a Randomized Controlled Lifestyle Intervention to Prevent Obesity among Chinese Primary School Students: CLICK-Obesity Study. PloS one 2015, 10(10):e0141421.

47. Lu C, Wang Z, Dong Y, Ma J: Prevalence of weight-loss behaviors and the associations betweenweight-loss behaviors and weight-related perceptions among students in primary and middle schools in China. Chinese Journal of School Health 2017, 3, 330-333.

48. Mushtaq MU, Gull S, Mushtaq K, Shahid U, Shad MA, Akram J: Dietary behaviors, physical activity and sedentary lifestyle associated with overweight and obesity, and their socio-demographic correlates, among Pakistani primary school children. The international journal of behavioral nutrition and physical activity 2011, 8:130.

49. Matheson DM, Killen JD, Wang Y, Varady A, Robinson TN: Children's food consumption during television viewing. The American journal of clinical nutrition 2004, 79(6):1088-1094.

\section{Supplementary Files}

This is a list of supplementary files associated with this preprint. Click to download.

- FoodFrequencyQuestionnaire.docx 